\title{
A Evaluation on the Impact of Social Media in Human Resource Management
}

\author{
Magdalene Peter, J Pavithra, Renju
}

\begin{abstract}
Social media became the wide spread in every aspect of business and thus in the area of Management of human resources. The aim of this research is to assess the impact of social media on HR tasks. The study of social media in HR is enabled to find the ways of using the social networking sites in HR field. This study mainly concentrates on studying the usage strategy of social network in Human Resource functions.
\end{abstract}

Keywords :Human resource management,Hiring,applicants.

\section{INTRODUCTION}

Social Media

Social media to the means of interaction in virtual communities and networks between individuals and organisations. These networks are used for data and thoughts creation, sharing and exchange. Andreas Kalpan and Michael Haenlein describe "the Internet group" as social media. Applications based on Web 2.0's ideological and technological foundations. Social media relies on mobile and web-based techniques to generate extremely interactive platforms that share, co-create, discuss and alter user-generated content.[1]

Social networking relates to using online social networks to interact with other individuals, such as Facebook, Twitter, Google+, LinkedIn. Blogs and methods to share text and thoughts, organizations, personal messaging, a chat facility and file or picture sharing features can be indulged by a social network. It is a web-based instruments and techniques for sharing data and transforming communication into interactive dialogs with external or internal audiences. It is the technology that enables users to share their ideas, work and multimedia, as well as comment on the content of others. Social media allows you to be part of distinct networks of like-minded individuals.[2]

Social media is something for an individual that allows information to be published, shared and commented online without the influence of editors, organizations or the state. Social media is a range of internet platforms that enable internet data to be published, shared and commented on, enabling organisations to interact with individual stakeholders.[3]

Social Media for Business

Social media is well created as a collection of instruments geared towards the customer and the brand. Social media is increasingly being provided as an innovative inner efficiency alternative. These social networking sites also provide an

Revised Manuscript Received on July 22, 2019.

Magdalene Peter Department of Management studies,Bharath Institute of Higher Education and Research,Chennai,India

J Pavithra, Department of Management studies,Bharath Institute of Higher Education and Research,Chennai,India

Renju, Department of Management studies,Bharath Institute of Higher Education and Research,Chennai,India enormous amount of target clients at a moment, so that company can be promoted. The main point is that social media allows a broad group of fellow experts to share questions, responses, thoughts and expertise, autonomous of geography and hierarchy, creative businesses are mining links on important social networking sites, preserving online reputation of organisations, and observing how their own talent interacts online.[4] They also use social media to build talented groups that engage passive applicants and encourage their brand. Corporate approaches to social media access differ as it was discovered in a study that most businesses enable some kind of access to social media at job in different degrees For example, $43 \%$ of staff operate in organisations where access to social media is fully available. Their access was supervised by 24 percent. Only 16 percent of businesses totally block access to social media at job for their staff.

Social Media in Human Resource Management[5]

There is a increasing phase in the use of social media in human resources. There are some places where social media has already created highways and there are few places that still need exploring. The avenues are explored by few organisations and few are apprehensive about using it. The reality continues, however, that social media provides a platform to be properly tapped. [6]The fields are recruitment, cooperation and communication, talent management and branding internally. Wipro Consulting Services performed a research to investigate the effect and significance of social media in four main HR fields within five sectors with a particular focus on the Indian market. The results reflect that three fields of Internal Branding, Collaboration and Communication and Hiring were deemed to be nearly equally suitable for social media use, with the most favored being Internal Branding. Among these, talent management was considered less suitable for using social media, and there was a distinction of view in the use of social media in various sectors.[7]

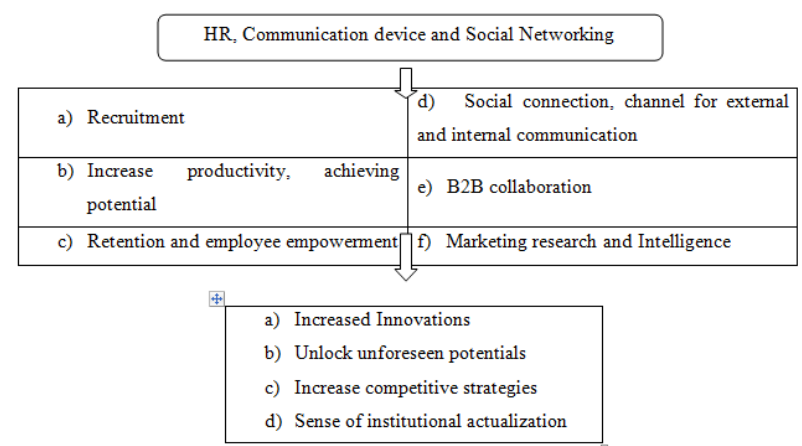

Fig. 1 - Diagram reflecting the benefits of social networking 
Social Media can be used as:

a) A Game Changer in Recruitment: Using social media has altered the work game - seekers and recruiters alike. The social media has provided HR professionals with the information about potential candidates the $\mathrm{A}$ range of candidate data as well as fresh ways to reach passive applicants and advertise the company's present openings. Even the social media checks the background of the applicants on prospective staff.[8]

b) Facilitator in Decision Making: Social media sites also provide a platform for corporate houses to share with them business data and work possibilities. Even most of the corporate agree that they have social sites for screening of potential candidates. This even helps the candidate to decide whether to go for interview by having the information through these social sites. Whereas the corporations also have a choice to accept or reject proposal Information found from their profiles on social media. However, while using social media to screen prospective applicants, the recruiters need to be highly cautious. On the other hand, it is also unfair to exclude prospective applicants simply because they have not jumped on the bandwagon of social media. [9]However, social media can be helpful and beneficial by receiving data from other applicants linked to prior job, background, education and suggestions when reviewing them on social media sites.

c) Bridging the Generation Gap: If, on the other side, we see a tech-savvy generation of staff bringing their social web conduct to the organisation and working styles.[10] On the other side, there are a substantial number of staff who are part of the generation of emails. The businesses look forward to maintaining their understanding and skills. This is how they distinguish the two groups. The first group needs and requests on - the-job social networking and is used to share transparently. The second group often refuses to use this social web even outside the workplace, and has always depended on emails to fulfill its needs.[11] Therefore, maintaining both groups will be a task where one moves towards retirement and the other is far from ready to alter employers. Organizations should not solely jump on the social media bandwagon and begin to use these free instruments every moment and everywhere. [12]

Five evolving problems that are critical for HR and a business to tackle in today's globe include: 1 . Competitive position of a business 2. Decentralization 3. Restructuring of an organization 4. Technology 5.

HR assesses these problems when they are in flux by assessing the inner and external variables that play a part in the evolving setting to tackle them properly.[13] HR is selective in its strategy to improve the efficiency of the business while staying compatible with the vision and goals of the business. [14]HR seeks to address emerging problems by promoting proactive rather than reactive behaviour, explicitly communicating business objectives, stimulating critical thinking, and constantly re-evaluating assumptions, identifying any gaps between present problems and their vision for the future, promoting leadership involvement, and identifying and identifying HR limitations and possibilities. [15]The effect of HR's role will show whether their attempts are effective as they eventually should assist the organisation identify fresh possibilities or assist the organisation address the environmental problems they face.[16]

\section{A.HR emerged as social HR}

Gamification Becomes A Standard Practice

In 2013, gamification continuously generated enormous inroads in many business processes. With more investigate, studies, and actual-world case showing the capacity to integrate game procedure into non-game behavior such as advertising, call center process and learning and development, a greater quantity of company procedures will start to "gamify."Deloitte is the firm that previously uses ramification, integrate levels, "badges" and top-scoring management boards into its "Deloitte management academy" that has taught more than 20,000 corporate customers since its founding in the past.[17] Deloitte and its customers can boast benefits as occupied staff who are dedicated to enhancing at job as a consequence of this endeavor.

The Death of the Resume

Recently, one's private brand's breadth and depth will replace the traditional resume. Expect a employ director or hiring executive to check one or more of the subsequent basis about the interviewee before interviewing a potential employer: 1) the top ten hunt on their names on either Google or Bing 2) the number of Twitter followers tweeted, 3) the amount and quality of the LinkedIn corporation, 4) the quantity and quality of recommendations on LinkedIn and 5) the score of Klout.Klout Score Will Become A Measurable Currency

The software firm Salesforce.com recently announced a stance that mentioned "a Klout rating of 35 or more" as one of the main "required abilities" for a community director role in the latest blog article on Personal Branding. As the largest player in the increasing globe of "digital impact," Klout score will discover a prominent position in the recommence and outline of LinkedIn in the coming days. For company experts, Klout calls itself the SAT score, measuring each user's internet "impact." A Klout score is a 1-100 statistical score that ranks on factors like: how many persons you achieve throughout public media; how greatly you trust; and on what subjects. Microsoft recently created a strategic investment in Klout, and Bing and Klout will associate to tighten up to community online explore.[18]

"Influence has become the social web's currency, and Klout is the normal measure for that," Joe Fernandez, CEO of Klout, said in a recent interview with Brian Solis. And he's all right. Soon we may all have the Klout app on our mobile phone and tablet, so we know instantly how our rating improves and falls every week.

Personal Branding will be a required Skill

Whether employers are more likely today to employ High IQ applicants or high Klout score. The balance will continue to tip towards the latter as employers, employees and job applicants devote more time, money and awareness to personal brand growthCompanies will follow the lead of PricewaterhouseCoopers, which holds an annual "Personal Branding Weak" in which a series of training sessions assist train prospective new hires to construct their personal brand and enhance their marketability. More forward-looking companies catch up with this kind of mutually beneficial training and use it as a point of differentiation in employing top Millennial talents Finally, expect to see this kind of program as part of the core curriculum at college campuses, as college advisors finally see work readiness as a serious element of their job. 
We are moving from an "data economy" to a "social economy," the line is quickly blurring between the significance of what we know and who we comprehendCurrently, prospective job applicants are much more prepared to build their "elevator pitch" and post this ad blur on Facebook, LinkedIn and their Twitter biosIf personal branding seems to be shallow, think againPutting significance on applicant networks and spheres of impact makes perfect sense in an age where crowd sourcing the right response to a problem is just as good as coming up with it yourself.[20] Recruiters will find you before you know you are looking for a job

Not only do candidates need to understand how to use social to their advantage; HR managers in charge of talent management also need to understand how to use social instruments to their advantage. Full companies are already cropping up to streamline the process for them. Start-ups like Entelo and TalentBin assist businesses discover eligible applicants by scanning social networks and highlighting certain candidates. Their search instruments consider the experience and background listed in user profiles, but also their use of the social network. These businesses can identify those who have recently or often updated their bios to determine which applicants are prepared to return to the work market.. Getting this head begin on head hunting is essential as the search for top applicants by top corporations becomes increasingly competitive. Companies are looking for which social media instruments are standard to follow in their businesses.[21]

Software analytics, single-stack software and any tool that enables easy and consistent collection and sharing of suitable data between departments is basically fantastic. It allows everybody to talk the same language on the same page. It's a great Leadership and HR tool. We can see what's going on throughout the organization - the good, the weird, the unbelievable, and the things that make us ask better questions.[22]

\section{II.BACKGROUND OF THE STUDY}

Social networking sites have become popular and the platforms change daily making the companies necessary to update regularly. The main motivation of this paper is the usage of social media and social network, in human resource functions. It has to be identified if social networks can help to reduce costs for a company in the HRM practices and which the proper ways of its usage are. Many users have their profiles to comment on the product reviews and customer service experiences. These profiles are more influential than the media itself. Li and Bernoff (2008) mentions in their book "Groundswell: Winning in a world Transformed by Social Technologies," that the social media can do good or bad to a company and offers various strategies to implement various platforms.

The biggest threat is anybody can post any feelings, which may be headlines for the journalist. Another threat is that most of the customers rely on product reviews and posting on the social media for information even for internal communication of policies within a company. Most of platforms are available at no cost for the companies to participate for good communication with audience for strong brand positioning. Most commonly used sites are Facebook, Twitter, LinkedIn, YouTube Channels and Blogs. These are used for several purposes like holding contests, engaging in conversation, updating, announcements about new products and service on Internet depending on the need and the audience.

Social media can be used for research purpose also. Social media study brings appropriate internet materials and blogging, social media platforms (e.g., Facebook, Twitter, YouTube), internet news sites (both professional and amateur), and face-to-face activities.It is quite obvious how much the social media is beneficial for the HR functions in the real life as well as corporate life. Though people are facing slight difficulty using this, it is highly inevitable in the current business scenario.[23]

\section{III.STATEMENT OF THE PROBLEM}

Companies generally incorporate social media in their human resource management with the assistance of technology to improve profitability and decrease expenses. However, this could not be accomplished easily in some sectors where HR innovation is not deemed a fresh force for achievement, but rather a pitfall to guarantee socio-economic achievement. Implementation of HRM technology. Therefore it is important to determine the results of Social HRM, the issue to be investigated is to examine whether Social HR gives beneficial or negative results to its customers. The problems that will be investigated in this article are the effects of social human resource leadership, the efficiency and possibilities that arise, and the HR features in the Socio-Technica[24]

\section{IV.SCOPE OF THE STUDY}

The research includes on a favorable note the effects and efficiency of social media in human resource management After a short literature review of the research, interviews are performed by preparing a questionnaire for HR experts, work consultancies and postgraduate learners to understand the fresh understanding or perception. On the role of social networking sites in HR tasks and recruitment. The most important factor that the range of social networking sites has is the most strong impact on efficient recruitment. The broader the range of social networking, the easier to reach more individuals[25]

\section{V.OBJECTIVES OF THE STUDY PRIMARY OBJECTIVE}

To study the effects and efficiency of social media in the field of human resource management secondary objectives: [ Study how social media is used in HR tasks ] To examine the problems encountered by using social media [ Study of the patterns of use of social media ] To study the efficiency of the recruitment system through social media

\section{RESEARCH METHODOLOGY}

\section{RESEARCH:}

Research is a method in which the scientists want to figure out the end outcome for a specified issue and thus the solution helps in future course of action. The study was described as "A careful investigation or enquiry especially through search for new facts in branch of knowledge". 


\section{VII.MEANING OF RESEARCH METHODOLOGY}

Methodology of research is a systematic way to solve a issue. It is a science of learning how to conduct research. Essentially, the method by which scientists go about their job of describing, explaining and predicting the phenomenon is called research methodology. It is also described as the research of techniques by which knowledge is acquired. Its primary goal is to offer the study job plan.[26][22]

\section{RESEARCH DESIGN}

The sort of Descriptive Research is used for this Statistical Research. The primary objective of this sort of studies is to define the information and features of what is being studied. The concept behind this kind of studies is to study frequencies, average and other statistical calculations. Descriptive research is performed primarily when a scientist wishes to obtain a better knowledge of a subject. It is quantitative and uses surveys and panels and also the use of probability sampling.

\section{A.Sampling technique:}

Sampling is the act, method, or method of choosing a appropriate sample, or a representative portion of a population for determining the parameters or features of the entire population. The sampling technique used here is random sampling and sampling of comfort.[27][21]

\section{B.Random sampling:}

A simple random sample is a subset of people selected from a bigger population. Each person is selected randomly and completely by chance, so that each person has the same likelihood of being selected at any point during the sampling phase. This method and method is referred to as simple random sampling.

\section{C.Convenience sampling:}

One of the primary kinds of non-probability sampling techniques is convenience sampling. A convenience sampling is made up of easily reachable individuals.[28][12]

\section{Sampling plan:}

A sampling plan is a detailed summary of which measurements will be taken at what time, what material, how, and by whom. Sampling plans should be designed in such a way that the resulting data will contain a representative sample of the parameters of interest and allow all questions to be answered as stated in the goals.

\section{E.Sample size:}

It represents the study's amount of participants. This research consists of 100 participants as the sample size.

SAMPLE SIZE DETERMINATION:

The sample size is given by the formula,

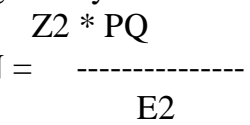

$\mathrm{P}=\%$ of population who answered favorably

$\mathrm{Q}=\%$ of population who answered unfavorably

$\mathrm{E}=$ Error level

The sample size has been calculated with the help of Question number 2 in the questionnaire

How useful is social media in showcasing employees' talent?

a) Not useful (2 respondents) \{ b) Useful c) Most useful \}

(23 respondents)

$\mathrm{P}=23 / 25=0.92$
$\mathrm{Q}=2 / 25=0.08$

$\mathrm{Z}=1.96 @ 5 \%$ Level of Significance

$$
\begin{array}{r}
1.962 * 0.92 * 0.08 \\
\mathrm{~N}= \\
--0.052
\end{array}
$$

This will be rounded near to 100 as a sample size.

\section{IX.DATA COLLECTION}

\section{F.Primary Source:}

To collect the information, survey technique is implemented. The primary data were gathered by distributing questionnaires to the participants. The questionnaire consisting of 22 questions beginning with the population information of various choices ; in addition, Likert - type scale questions.

\section{G.Secondary Source:}

Secondary data relates to information gathered by someone other than the consumer. Secondary data is one that already exists such papers and websites. The main sources of secondary information were articles, publications, web searches and literature assessment.

\section{X.QUESTIONNAIRE}

A questionnaire is a series of issues that are asked to people to acquire statistically helpful data about a specified subject. When correctly built and administered, the questionnaire becomes a essential tool through which statements can be made about particular organizations or individuals or entire populations.[29][30]

\section{H.Tools used:}

Percentage method
Chi-square method
$\square \quad$ Weighted average method
$\square \quad$ One - way ANOVA Test
Two - way ANOVA Test
$\square \quad$ Kolmogorov - Smirnov Test
Correlation Analysis

\section{XI.REVIEW OF LITERATURE}

Muzna Zafar and Nupur Rastogi (2014), In their research of social media and HR practices, they studied the evolution of social media, its use for HR activities and organizational branding. This research guarantees that candidates ' recruitment and screening are the places where social media makes their presence felt. For recruitment organisations it is possible to target candidates, source passive and active applicants in accordance with the organisations'brand and strategy. The research indicates that to cope with this organisation, it is necessary to strategically frame policies and raise awareness about the use of social media, train executives on the company's social media strategy and document all policies, processes and practices. As in the current situation, avoiding such networking will not be a feasible option for businesses. 
Dr. T. Uma devi (July 2015) Discussed how HR emerged as a social HR and Google's data-driven human analytics strategy. 2011 was the year of' personnel development,' with extra businesses testing with the use of social medium to sort and advertise their organisations. In 2011, as' communal HR,' businesses concentrate on the social dimension, with organisations incorporating social technologies into their recruitment, Develop and hire staff. 2014 marks the start of ' people analytics ' in the ever-dynamic HRM sector, and 2015 has continually demonstrated its diverse company dimensions. Global demand and supply variables, changes in the environment, demographic differences, Changing lifestyles, individual views of individuals, and technological convergence are the megatrends that currently shape HRM. This research concludes that the HRM sector is reengineering to face the difficulties of ever-changing company landscape. Devpriya Dey (November 2014) article aims to understand the employees' perception towards the social media application practices that were identified. The study concludes that majority of the HR professionals agree that social media is relevant in the area of HR therefore they use it in their organizations. Induction and Compensation \& Benefits were deemed least suited among these for using social media. In regards to the employees perception towards the effort improvised by the HR fraternity via social media applications, talent management and talent transformation through knowledge sharing and creating a "power of one" culture is the most agreed ones. At the same time they also agree if a robust social media policy does not exist it might lead to wastage of productive time as well as leakage of confidential organization information too.

Dr. N. Srividya, Dr. Rita Basu (2014) illustrates all the usages of the social media not in daily life or personal life, but in business especially in HR functions. This paper concentrates only on the positive things of the social media that too in HR arena. This paper took a random sample of $104 \mathrm{HR}$ professionals is considered and a questionnaire was circulated among them to collect the data. The study tells that social media can be used for research purpose also. The study found that it is quite obvious how much the communal medium is beneficial for the HR functions in the real life as well as corporate life. Social media is gaining importance in the production world. People use it for several purposes.. It is not about whether to adopt social media or not. It is all about how to and how quickly we can.

Dr.Seyni Mamoudou, Dr.G.P.Joshi (2014) Their research concentrated on the use of IT instruments in the HR sector, the effectiveness of the use of HR IT instruments, the help of HR IT application management, the benefits and disadvantages of the use of HR IT instruments, the implementation of HR IT instruments and HR IT tools versus HR strategic objectives. The research shows that businesses are using HR IT instruments and should contain all HR processes that will support all components of HR within the business from "Recruit to Retire" tasks. The study shows that the significance of HR-IT use is becoming more and more crucial not only because HR increases productively, but also because the value of the organisation rises, Including the most significant asset - human capital. The research concludes that globalization requires thinking about how IT can contribute to the satisfaction of business strategy in the human resource management framework in order to guide the company towards excellence and achieve competitiveness on the market.[32][15]

Brijmohan Vyas et al. (April 2015) Explains that the recruitment process is carried out by organisations using social media networking sites. This research discusses the consciousness of social media recruitment. Social media for hiring process is a win - win for both business and potential applicants. Instead of depending strongly on internal recruitment firms or work boards, this research concludes that many firms focus on finding specific talent through social media sites such as LinkedIn. This article concludes that most leadership, consultants and graduate and postgraduate learners are conscious of social recruitment through multiple social networking sites.. Job consultants and HR executives are disclosed their view that recruiting through social sites will become more efficient in HR tasks and the business will have low recruitment costs compared to other traditional recruitment techniques. Management and consultancies are prepared to introduce this modern method, but they think they need to know.

Faruk Bhuiyan et al. (2014 Analyzed historical information gathered from various published and unpublished sources. The research discovered that HRIS arose in the low-cost age (1980-90) and the roles of HR experts converted from traditional administrative to more strategic positions during the high-tech age (1990). The word staff and staff management were used during the parliamentary period (1960-1980). Replaced by the word human resources and human resource management. During the low-cost age (1980-1990), HR agencies approached under pressure to connect with technology that became cheaper and more efficient and desired cost - efficient HR software. HRIS became common in the 1980s to satisfy HR demand with the popularity of Enterprise Resource Management (ERP) applications and the shift from mainframe systems to customer - server technology.

Casius Darroux (2013) attempted to study and analyze the management of human resource in the advent of social networking from a business context. The article suggests that the human resource personnel need to be able to tap on their network of experts; encourage employees to readily collaborate regardless of their demographic locationTo get quick feedback from clients on fresh products and services. The author also indicates promoting the beneficial use of social media by encouraging staff to come up with ways to better use these instruments to do their employment. These attempts can be concentrated on function or interest, As required and by following the leadership of so many innovative organisations and running a competition for the best fresh concepts. This strategy will definitely appeal to those staff who are most likely to use social media, encouraging confidence in the objectives of the rules that are eventually set up.

Soumi Rai (2011tried to comprehend employee engagement and social media ideas while outlining the unique features of Generation $Y$ and their influencing factors in the organisational framework. The article also explores briefly the difficulties encountered by HR experts in a nation like India with a burgeoning Gen Y workforce.

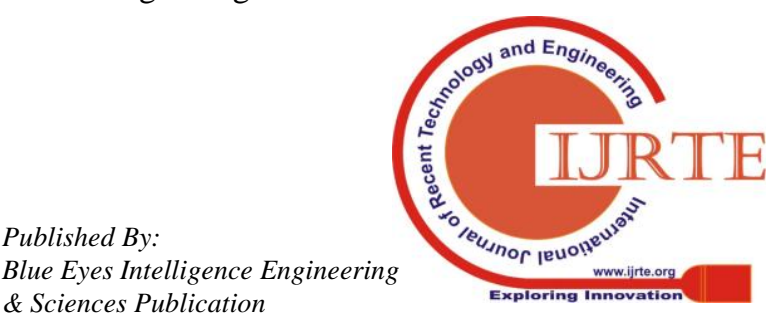


The research claims that the organisations are still struggling with this new medium that has grown exponentially over the previous decade. In reality, most businesses are still uncertain as to whether this medium is really required as a mode of internal communication and this can have a real effect on employee engagement proceduresWith Gen Y quickly growing Numbers across the workplace, it is time for organizations to pause and reflect on their future course of action to engage a generation that is highly wired, connected and unconventional. The research concludes that if young people can share data quickly through this medium for being part of an internal motion, organisations can very well understand what consequences this medium can have in forming attitudes about staff brands and company status.

Maxim Wolf et al. (2014) Focus on understanding the role of social media in HRM, specifically contributing to the strength of HRM through social media use. Considering social media as an information system generated by the user and HRM as a communication systemThe three-dimensional framework combines HRM's hierarchical structure, the temporal nature of HRM processes and HRM communications instructions. High Performance Working System (HPWS) encapsulates this suggested structure As a communications system between HR and staff. It enables vertical alignment of HPWS to be evaluated as well as horizontal alignment of HR operations throughout the Employee Life Cycle. In practice, focusing on techniques, what Technologies are used as opposed to what technologies could and should be used, enabling a greater knowledge of real-life and continuing social media phenomenon in organisations.

Archana L et al. (2013) addressed pre-hire measures of applicants ' amount and quality, with a particular focus on E-recruitment. E - Recruitment systems are used to promote and enhance the management of human resources. This article concludes with many businesses concentrating on finding specific talent through social media sites instead of relying strongly on internal recruitment firms or work boards. Employers use these sites to define talent, but some use targeted and innovative social media campaigns to attract talentEngaging and challenging applicants and finding the correct organizational fit. By making it more open and democratic, social media has enhanced the recruitment process ; improving the visible pool of talent from which to participate and recruit. It's the way we're doing company today.

Khalil Ghazzawi et al. (2014) Evaluated current and emerging Electronic Human Resource Management ideas in Lebanese organisations and studied how they shape the values, perceptions and behaviors of staff. This article examined the positive variables that affect the efficiency of the dashboards and backgrounds for human resources Employees use them and see the effect and results of technology on the level of motivation of staff. The findings of this article proposed a powerful impact on the attitudes of staff to use the E - HRM from perceived ease of use of digital human resource leadership. This document revealed that perceived user-friendliness is more essential than perceived usefulness; it is the primary predictor of the approach towards electronic human resource management. This document proposes that the E-HR alternatives should be flexible so that staff feel comfortable while practicing such a scheme and that better organisational structure should be taken into account to guarantee that E-HRM is effective.

\section{XII.LIMITATIONS OF THE STUDY}

Some participants may conceal the actual data.

Sometimes people didn't have time to fill out the questionnaire, so they could tick the option without even reading the question.

A sample size can not represent the entire population at all times.

One of the limitations in undertaking the studies was time and money.

The findings are based on only the information given by the respondents.

TABLE 1: Shown that distribution of respondents based on Naukri.com

\begin{tabular}{|c|c|c|c|c|c|}
\hline & occurrence & Percent & Valid Percent & $\begin{array}{l}\text { collective } \\
\text { Percent }\end{array}$ \\
\hline \multirow[t]{6}{*}{ Valid } & Most visited site & 62 & 62.0 & 62.0 & 62.0 \\
\hline & 2nd choice & 29 & 29.0 & 29.0 & 91.0 \\
\hline & 3rd choice & 5 & 5.0 & 5.0 & 96.0 \\
\hline & 4th choice & 2 & 2.0 & 2.0 & 98.0 \\
\hline & Least visited site & 2 & 2.0 & 2.0 & 100.0 \\
\hline & Total & 100 & 100.0 & 100.0 & \\
\hline
\end{tabular}

Fig I: Shown that Involvement of respondents based on Naukri.com:

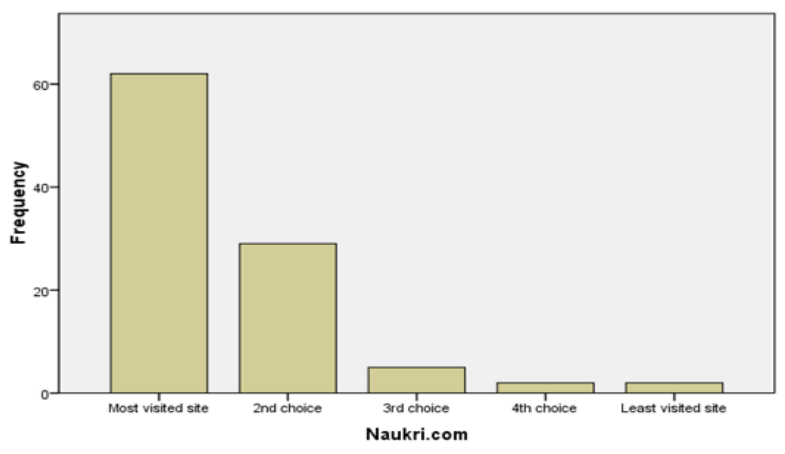

INTERPRETATION:

It is noted that $62 \%$ of participants have Naukri.com as the most visited site, $29 \%$ of participants have Naukri.com as a 2nd selection, $5 \%$ of participants have Naukri.com as a 3rd option, $2 \%$ of participants have Naukri.com as a 4 th option and $2 \%$ of participants think that Naukri.com is the least visited site.

TABLE 2: Show that Monster.com-based distribution of respondents:

Monster.com

\begin{tabular}{|c|c|c|c|c|c|}
\hline & & occurrence & Percent & Valid Percent & $\begin{array}{l}\text { Cumulative } \\
\text { Percent }\end{array}$ \\
\hline \multirow[t]{5}{*}{ Valid } & Most visited site & 24 & 24.0 & 24.0 & 24.0 \\
\hline & 2nd choice & 38 & 38.0 & 38.0 & 62.0 \\
\hline & 3rd choice & 33 & 33.0 & 33.0 & 95.0 \\
\hline & 4th choice & 5 & 5.0 & 5.0 & 100.0 \\
\hline & Total & 100 & 100.0 & 100.0 & \\
\hline
\end{tabular}


Fig.2: Shown that allotment of respondents based on Monster.com:

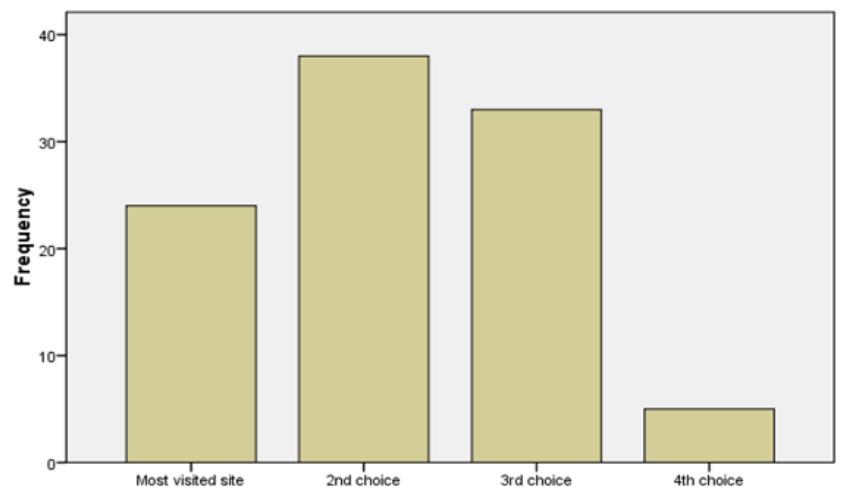

INTERPRETATION:

It is observed that $24 \%$ of the respondents have Monster.com as most visited site, $38 \%$ of the respondents have Monster.com as a 2 nd choice, $33 \%$ of the respondents have Monster.com as 3 rd choice and $5 \%$ of the respondents have Monster.com as 4th choice.

TABLE 3.: Shown that distribution of respondents based on Shine.com

\begin{tabular}{|c|c|c|c|c|c|}
\hline & & Frequency & Percent & Valid Percent & $\begin{array}{l}\text { Cumulative } \\
\text { Percent }\end{array}$ \\
\hline \multirow[t]{6}{*}{ Valid } & Most visited site & 10 & 10.0 & 10.0 & 10.0 \\
\hline & 2nd choice & 34 & 34.0 & 34.0 & 44.0 \\
\hline & 3rd choice & 51 & 51.0 & 51.0 & 95.0 \\
\hline & 4th choice & 4 & 4.0 & 4.0 & 99.0 \\
\hline & Least visited site & 1 & 1.0 & 1.0 & 100.0 \\
\hline & Total & 100 & 100.0 & 100.0 & \\
\hline
\end{tabular}

Fig 3: Shown that distribution of respondents based on Shine.com

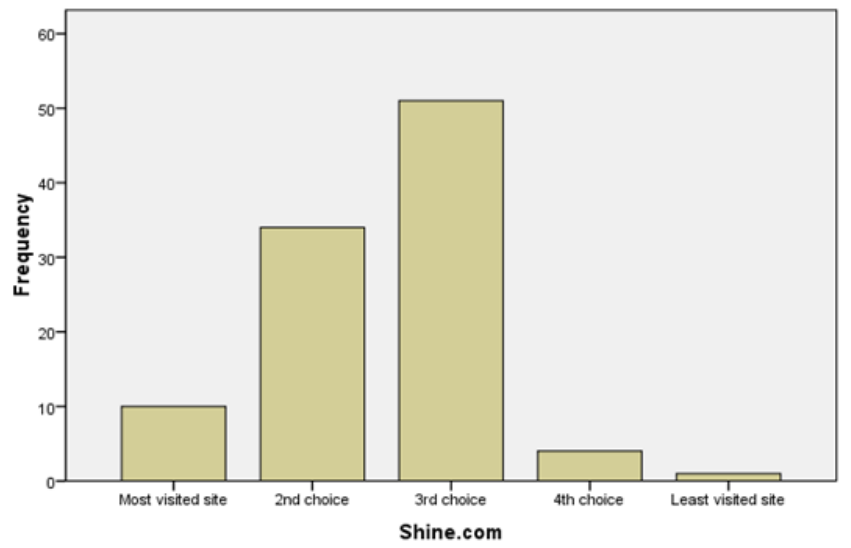

\section{INTERPRETATION:}

It is observed that $10 \%$ of the respondents have Shine.com as most visited site, $34 \%$ of the respondents have Shine.com as a 2 nd choice, $51 \%$ of the respondents have Shine.com as a 3 rd choice and $4 \%$ of the respondents have Shine.com as the least visited site.

TABLE 4: Shown that distribution of respondents based on Times Job:

\begin{tabular}{|ll|l|l|l|l|}
\hline & Frequency & Percent & Valid Percent & $\begin{array}{l}\text { Cumulative } \\
\text { Percent }\end{array}$ \\
\hline Valid & Most visited site & 3 & 3.0 & 3.0 & 3.0 \\
2nd choice & 1 & 1.0 & 1.0 & 4.0 \\
3rd choice & 5 & 5.0 & 5.0 & 9.0 \\
4th choice & 54 & 54.0 & 54.0 & 63.0 \\
Least visited site & 37 & 37.0 & 37.0 & 100.0 \\
Total & 100 & 100.0 & 100.0 & \\
\hline
\end{tabular}

Fig.4: Shown that distribution of respondents based on Times Job:

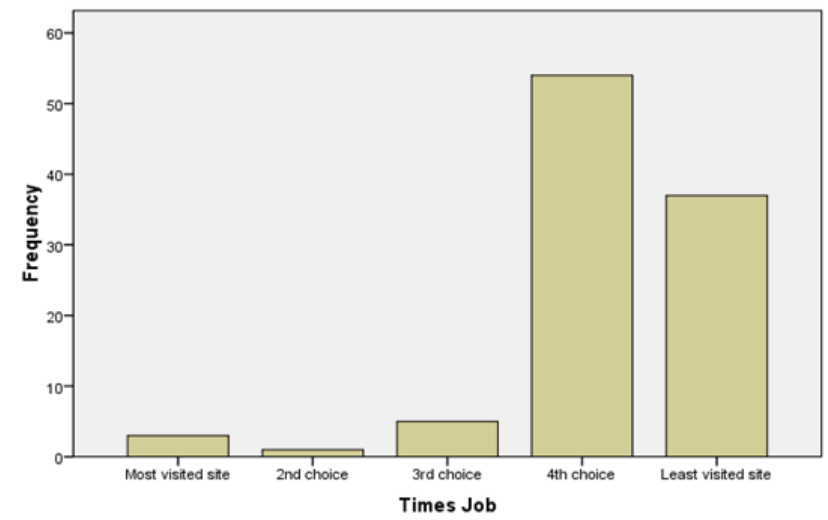

INTERPRETATION:

It is observed that $3 \%$ of the respondents have Times Job as the most visited site, $1 \%$ of the respondents have it as a 2 nd choice, $5 \%$ of the respondents it as a 3 rd choice, $54 \%$ of the respondents have it as a 4th choice and $37 \%$ of the respondents feel Times Job as the least visited site.

TABLE 5: Shown that distribution of respondents based on sourcing applicants' resume:

Used for sourcing resume of applicants

\begin{tabular}{|c|c|c|c|c|c|}
\hline & Frequency & Percent & Valid Percen & $\begin{array}{l}\text { Cumulative } \\
\text { Percent }\end{array}$ \\
\hline \multirow[t]{4}{*}{ Valid } & Strongly Agre & 41 & 410 & 410 & 410 \\
\hline & Agree & 55 & 55.0 & 55.0 & 96.0 \\
\hline & Neutral & 4 & 4.0 & 4.0 & 100.0 \\
\hline & Total & 100 & 100.0 & 100.0 & \\
\hline
\end{tabular}

Fig 5: Shown that distribution of respondents based on sourcing applicants' resume: 
A Evaluation on the Impact of Social Media in Human Resource Management

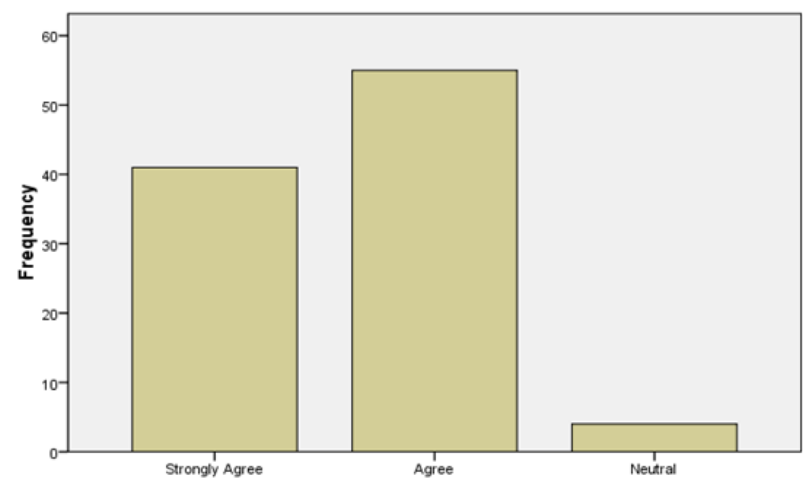

Used for sourcing resume of applicants

INTERPRETATION:

It is noted that 41 percent of participants are highly in agreement and 55 percent of participants are in agreement that social media is used to supply applicants ' resumes. Four percent of participants are neutral about the use of social media to obtain applicants ' resumes.[31]

TABLE 6: Shown that distribution of respondents based on applicants' contact details:

Contact details of applicants can be obtained

\begin{tabular}{|ll|l|l|l|l|}
\hline & & Frequency & Percent & Valid Percent & $\begin{array}{l}\text { Cumulative } \\
\text { Percent }\end{array}$ \\
\hline Valid & Strongly Agree & 71 & 71.0 & 71.0 & 71.0 \\
& Agree & 28 & 28.0 & 28.0 & 99.0 \\
Neutral & 1 & 1.0 & 1.0 & 100.0 \\
Total & 100 & 100.0 & 100.0 & \\
\hline
\end{tabular}

Fig 6: Shown that distribution of respondents based on applicants' contact details:

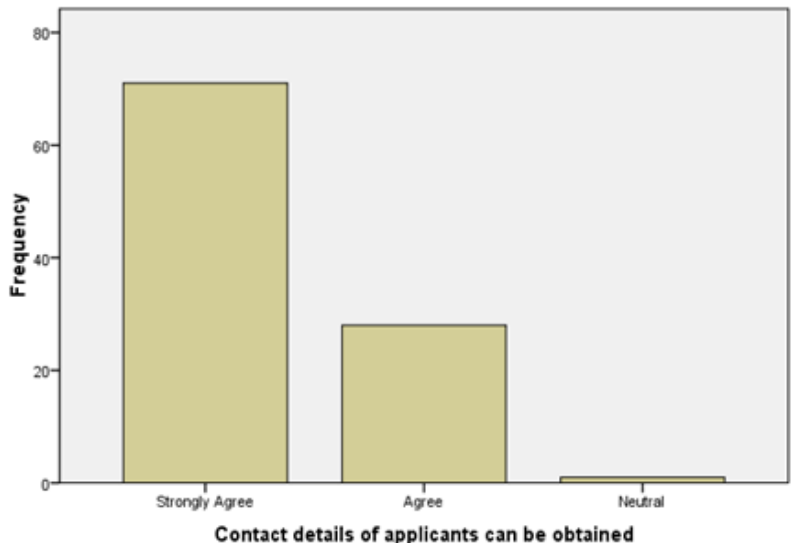

INTERPRETATION: It is observed that $71 \%$ of respondents are very much in agreement and $28 \%$ of respondents agree that social media is useful in obtaining contact data from candidates.One percent of participants felt neutral that contact information could be acquired through social media.

TABLE 7: Shown that distribution of respondents based on maintaining company's homepage:

Used for maintaining company's homepage

\begin{tabular}{|ll|l|l|l|l|}
\hline & & Frequency & Percent & Valid Percent & Cumulative Percent \\
\hline Valid & Strongly Agree & 48 & 48.0 & 48.0 & 48.0 \\
& Agree & 46 & 46.0 & 46.0 & 94.0 \\
Neutral & 3 & 3.0 & 3.0 & 97.0 \\
Disagree & 3 & 3.0 & 3.0 & 100.0 \\
Total & 100 & 100.0 & 100.0 & \\
\hline
\end{tabular}

Fig 7: Shown that distribution of respondents based on maintaining company's homepage:

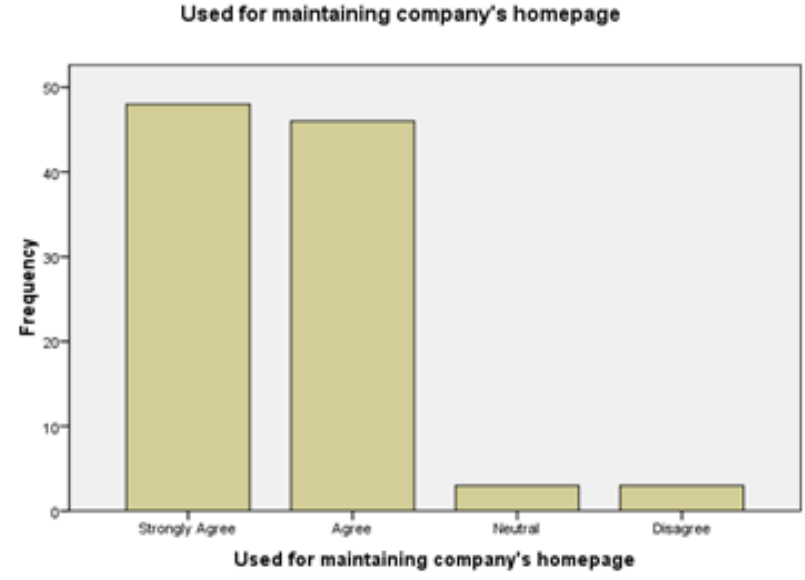

\section{INTERPRETATION:}

It is noted that $48 \%$ of participants are highly in agreement and $46 \%$ of participants agree that social media is used to update and maintain the homepage of the company. 3\% of participants are neutral and 3\% disagree with the use of social media to maintain the homepage of the company.

TABLE 8: Show that recruitment-based allocation of participants:

Social media is used for Recruitment process

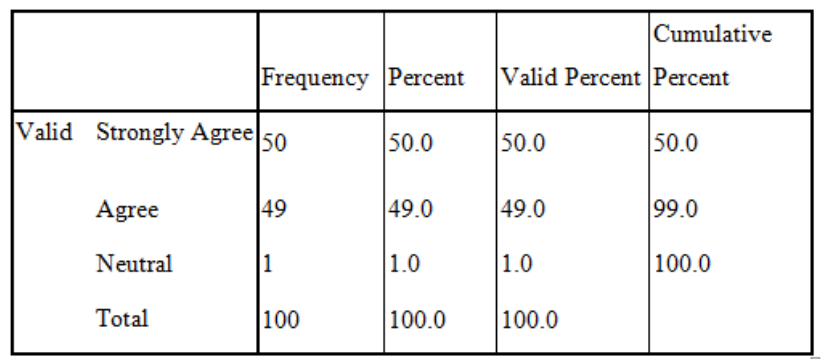

Fig.8: Shown that distribution of respondents based on Recruitment process

\section{INTERPRETATION:}

It is noted that $50 \%$ of participants highly agree that social media is used in the recruitment system, $49 \%$ of participants agree that social media is used in the recruitment system and $1 \%$ of participants are neutral that social media is used in the recruitment process.

TABLE 9: Display of participants based on Social Media Effectiveness in Recruiters 
Fif.9 Social media is effective force in Recruitment Process

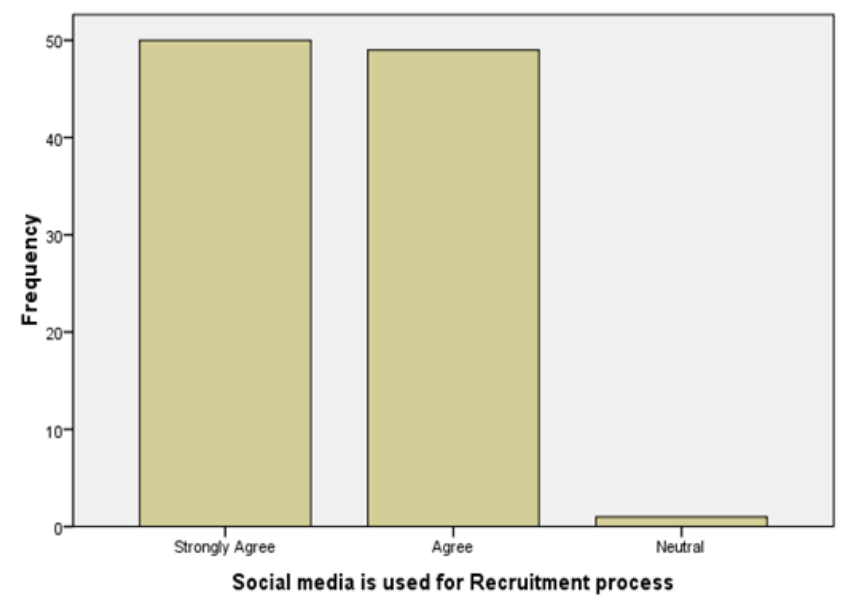

INTERPRETATION:

It is noted that $50 \%$ of participants highly agree that social media is used in the recruitment system, $49 \%$ of participants agree that social media is used in the recruitment system and $1 \%$ of participants are neutral that social media is used in the recruitment process.

TABLE 10: Display of participants based on Social Media Effectiveness in Recruiters

Social media is effective force in Recruitment process

\begin{tabular}{|ll|l|l|l|l|}
\hline & & Frequency & Percent & Valid Percent & Cumulative Percent \\
\hline Valid & Strongly Agree & 80 & 80.0 & 80.0 & 80.0 \\
& Agree & 18 & 18.0 & 18.0 & 98.0 \\
& Neutral & 2 & 2.0 & 2.0 & 100.0 \\
Total & 100 & 100.0 & 100.0 & \\
\hline
\end{tabular}

Fig.10: Shown that distribution of respondents based on Effectiveness of Social Media in Recruitment:

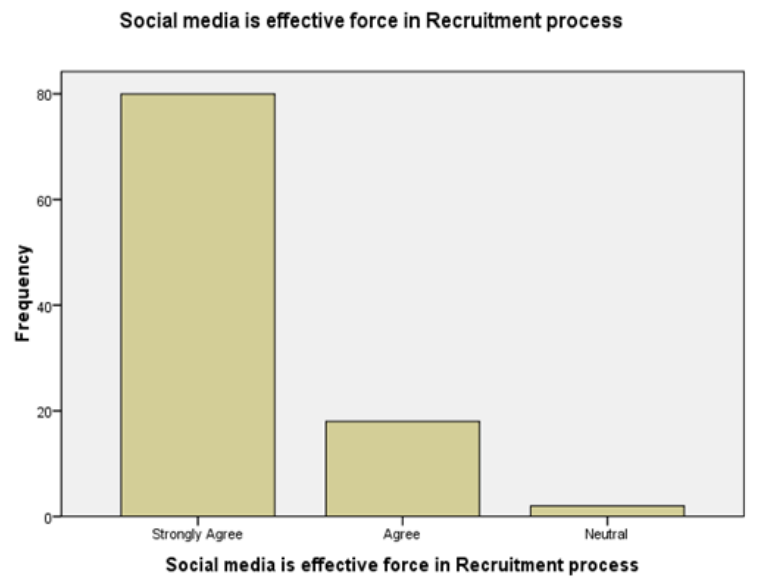

\section{INTERPRETATION:}

It is noted that $80 \%$ of participants are highly in agreement and $18 \%$ of participants agree that social media is an efficient force in the recruitment process and $2 \%$ of participants are neutral that social media is an efficient force in the recruitment process.

TABLE 11: Shown that distribution of respondents based on HR - Marketing cost:

HR - Marketing cost have decrease

\begin{tabular}{|ll|l|l|l|l|}
\hline & Frequency & Percent & Valid Percent & $\begin{array}{l}\text { Cumulative } \\
\text { Percent }\end{array}$ \\
\hline Valid & Strongly Agree & 29 & 29.0 & 29.0 & 29.0 \\
& Agree & 62 & 62.0 & 62.0 & 91.0 \\
Neutral & 8 & 8.0 & 8.0 & 99.0 \\
Disagree & 1 & 1.0 & 1.0 & 100.0 \\
Total & 100 & 100.0 & 100.0 & \\
\hline
\end{tabular}

Fig.11: Shown that distribution of respondents based on HR Marketing cost:

HR - Marketing cost have decreased

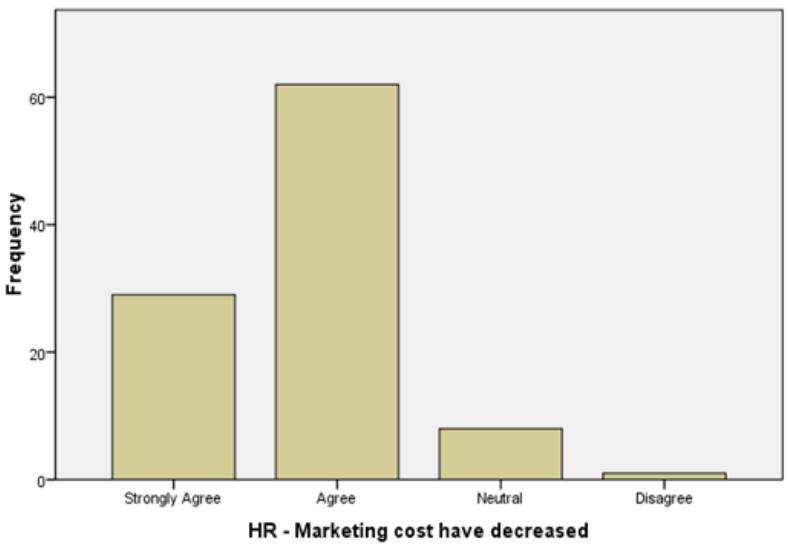

INTERPRETATION:

It is noted that 29 percent of participants are heavily in agreement and 62 percent of participants agree that the price of HR-marketing has fallen. $8 \%$ of participants are neutral and $1 \%$ of participants disagree with the decrease in $\mathrm{HR}$-marketing costs.

TABLE '12: Show that the price of general recruitment was reduced by the allocation of participants:

General Recruitment cost have decrease

\begin{tabular}{|ll|l|l|l|l|}
\hline & Frequency & Percent & Valid Percent & $\begin{array}{l}\text { Cumulative } \\
\text { Percent }\end{array}$ \\
\hline Valid & Strongly Agree & 29 & 29.0 & 29.0 & 29.0 \\
& Agree & 65 & 65.0 & 65.0 & 94.0 \\
$\begin{array}{l}\text { Neutral } \\
\text { Total }\end{array}$ & 6 & 6.0 & 6.0 & 100.0 \\
\hline
\end{tabular}

Fig 12: Shown that distribution of respondents based on General Recruitment cost: 


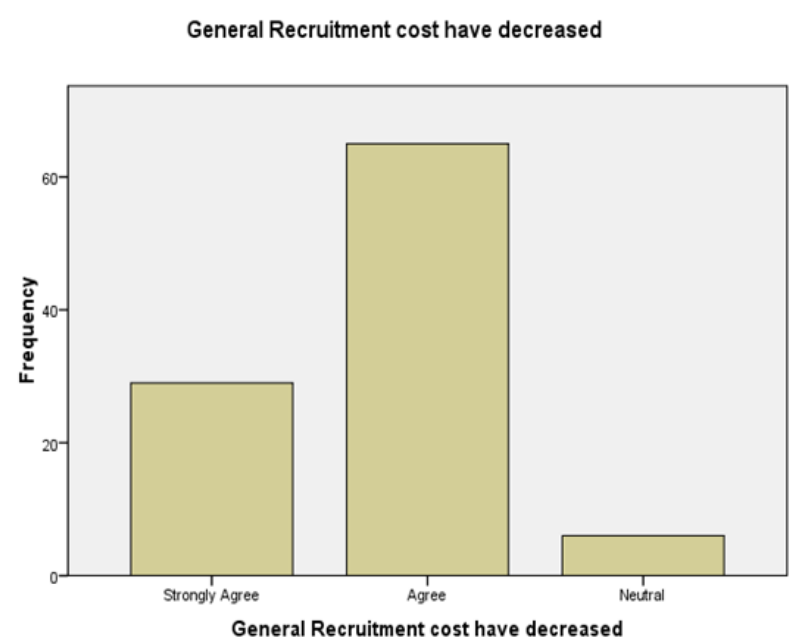

INTERPRETATION:

It is noted that 29 percent of participants are heavily in agreement and 65 percent of participants agree that the overall price of recruitment has fallen.6\% of the respondents are neutral that the general recruitment cost has decreased using social media.

TABLE 13: Shown that distribution of respondents based on Cost per Hire:

Cost Per Hire is decrease

\begin{tabular}{|ll|l|l|l|l|}
\hline & Frequency & Percent & Valid Percent & $\begin{array}{l}\text { Cumulative } \\
\text { Percent }\end{array}$ \\
\hline Valid & Strongly Agree & 74 & 74.0 & 74.0 & 74.0 \\
& Agree & 23 & 23.0 & 23.0 & 97.0 \\
Neutral & 3 & 3.0 & 3.0 & 100.0 \\
Total & 100 & 100.0 & 100.0 & \\
\hline
\end{tabular}

Cost Per Hire is decreased

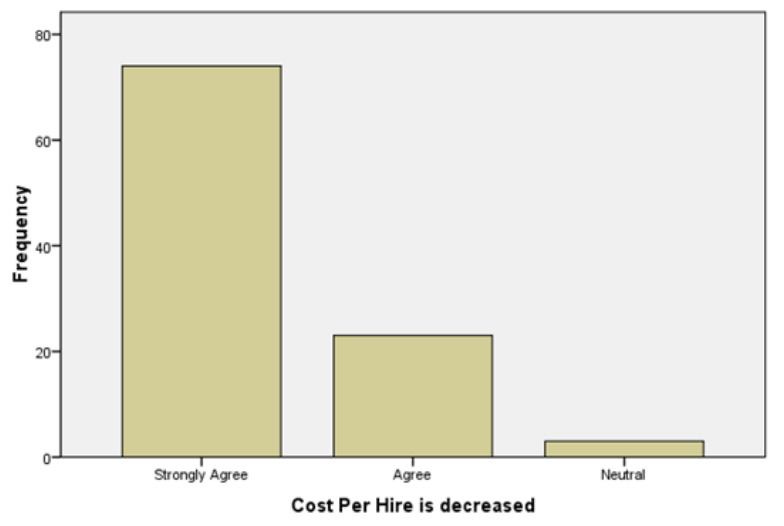

FIG.13

INTERPRETATION:

It is noted that 74 percent of participants are highly in agreement and 23 percent of participants agree that social media use to reduce the price per hire. In the recruitment phase, $3 \%$ of participants are positive about the price per hire being reduced using social media.

TABLE 14: Show that time-to-hire allocation of participants: Time to Hire is decreased[32]

\begin{tabular}{|c|c|c|c|c|c|}
\hline & & Frequency & Percent & Valid Percent & $\begin{array}{l}\text { Cumulative } \\
\text { Percent }\end{array}$ \\
\hline \multirow[t]{5}{*}{ Valid } & Strongly Agree & 40 & 40.0 & 40.0 & 40.0 \\
\hline & Agree & 54 & 54.0 & 54.0 & 94.0 \\
\hline & Neutral & 5 & 5.0 & 5.0 & 99.0 \\
\hline & Disagree & 1 & 1.0 & 1.0 & 100.0 \\
\hline & Total & 100 & 100.0 & 100.0 & \\
\hline
\end{tabular}

Fig.14: Shown that distribution of respondents based on Time to Hire:

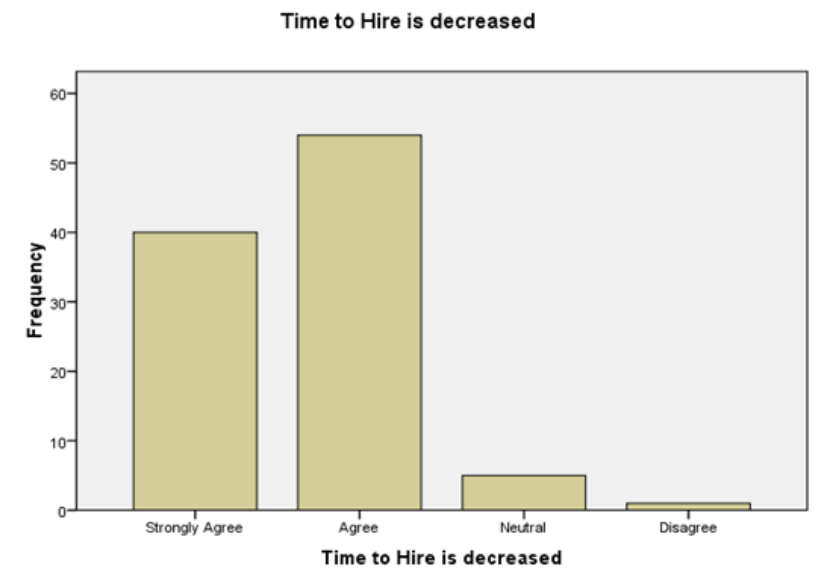

INTERPRETATION:

It is noted that 40 percent of participants are highly in agreement and 54 percent of participants agree that in the recruitment phase using social media, the time to employ is reduced. $5 \%$ of participants are neutral and $1 \%$ disagree with the decrease in hiring time in social media recruitment processes.

\section{RESULTS}

The majority of participants, i.e. $89 \%$ of participants belong to the $20-30$ age group and $11 \%$ of participants belong to the $31-40$ age group.

$\square$ Thirty-nine percent of participants have one year of experience and sixty-one percent have two to five years of experience.

$54 \%$ of participants spend $3-6$ hours on the web and $36 \% 7-10$ hours on the web.

Almost 21 percent of participants agree that networking sites are helpful for showcasing the talent of staff and 79 percent agree that networking sites are most helpful for showcasing the talent of staff.

$46 \%$ of participants highly agree that networking sites are used for surfing and $54 \%$ agree that networking sites are used for surfing.

Sixty-six percent of participants highly agree that websites are used to verify work portals.

Approximately 53\% of participants highly agree and $42 \%$ agree that data from rivals is collected through social media.

Approximately $78 \%$ of participants highly agree and $20 \%$ agree that social media is used to post work vacancy advertising. 
Approximately $22 \%$ of participants highly agree and $62 \%$ agree that it takes a lengthy time to sort out the data needed.

Approximately $17 \%$ of participants highly agree and $64 \%$ agree that the information obtained through social networks is enormous.

Approximately $52 \%$ of participants agreed that clear data on applicants could be obtained. 5\% Of the participants are neutral[33]

Approximately $53 \%$ of participants agree that applicants can acquire prior job experience via social media. $4 \%$ The view of the participants is neutral. About $55 \%$ of participants are firmly in agreement and $9 \%$ of participants are neutral and $1 \%$ disagree with the views.

Approximately $47 \%$ of participants highly agree and $50 \%$ agree that candidates ' academic qualifications are disclosed via social media. $2 \%$ of the participants were neutral and $1 \%$ disagreed with the view.

$52 \%$ of participants highly agreed and $39 \%$ agreed that the details conducted by the project were acquired. Seven percent of participants are neutral and two percent disagree with the views.

$\square \quad$ LinkedIn is the third option for about $5 \%$ of participants, LinkedIn is the fourth option for $34 \%$ of participants and LinkedIn is the least visited location for $60 \%$ of participants.

$62 \%$ of participants had Naukri.com as their most frequently visited site, $29 \%$ had Naukri.com as their second option, $5 \%$ had Naukri.com as their third option,

$2 \%$ of the respondents have Naukri.com as a 4th choice and $2 \%$ of the respondents feel Naukri.com as a least visited site.

$24 \%$ of the respondents have Monster.com as most visited site, $38 \%$ of the respondents have Monster.com as a 2nd choice, $33 \%$ of the respondents have Monster.com as 3rd choice and $5 \%$ of the respondents have Monster.com as 4th choice.

$10 \%$ of the respondents have Shine.com as most visited site, $34 \%$ of the respondents have Shine.com as a 2 nd choice, $51 \%$ of the respondents have Shine.com as a 3 rd choice and $4 \%$ of the respondents have Shine.com as the least visited site.

$3 \%$ of the respondents have Times Job as the most visited site, $1 \%$ of the respondents have it as a 2 nd choice, $5 \%$ of the respondents it as a 3rd choice, $54 \%$ of the respondents have it as a 4 th choice and $37 \%$ of the respondents feel Times Job as the least visited site.

About 41 percent of participants highly agree and 55 percent agree that social media is used to obtain applicants ' resumes.

Approximately $71 \%$ of participants highly agree and $28 \%$ agree that social media is helpful in acquiring applicants ' contact information.

There is strong agreement among $48 \%$ of participants and $46 \%$ of participants that social media is used for updating and maintaining company' s homepage.

Approximately $50 \%$ of participants highly agree that social media is used for recruitment, and $49 \%$ agree that social media is used in recruitment.

Eighty percent of participants are heavily in agreement and eighteen percent of participants agree that social media is an effective force in the recruitment process and two percent of participants are neutral about social media being efficient.
About 29 percent of participants highly agree and 62 percent agree that the price of HR - marketing has fallen.

About 29 percent of participants highly agree and 65 percent agree that the overall price of recruitment has fallen.

Seventy-four percent of participants highly agree and 23 percent agree that social media costs per hire are reduced.

About $40 \%$ of participants highly agree and $54 \%$ agree that hiring time is reduced in social media recruitment processes.

Approximately $39 \%$ of participants highly agree and $58 \%$ agree that the time of administration of the applicant is reduced using social media in the recruitment process.

$61 \%$ of the participants were heavily in agreement and $32 \%$ agreed that

It is found that there is significant difference between decreased general recruitment cost and decreased hiring time.

It is found that there is no significant difference between long time taken for sorting information and data acquired from social network is huge.

It is found that there is no significant difference between verifying job portals and posting advertisement regarding job vacancy.

It is found that that Naukri.com is the most visited site, Monster.com is the 2 nd choice of site, Shine.com is the 3rd choice of site, Times Job is the 4th choice of site and LinkedIn is the least visited site for Recruitment process.

$\square \quad$ It is found that there is no significant difference between the decreased HR - Marketing cost and decreased cost per hire.

It is found that there is no significant difference between gathering competitor' $\mathrm{s}$ information and maintaining company' s home page.

It is found that there is no significant difference between decreased time for applicant administration and decreased time for advertisement.

It is found that the huge data acquired through social network follows normal distribution.

It is found that the obtained back ground information of the candidates follows normal distribution.

It is found that there is a positive correlation between social media usefulness in showcasing employees' talent and social media usefulness in revealing educational qualification of candidates.

\section{DISCUSSION}

Companies should embrace contemporary recruitment methods of social networking sites, which are cheaper alternative recruitment methods rather than advertising in journals or fresh channels leading to higher costs.

The HR office should provide staff with a training program to teach them how to use the new scheme.

The training programs should not be carried out in small teams at once, so the employee can easily understand the new system.

The HR department must enforce processes to enable staff to plan their careers.

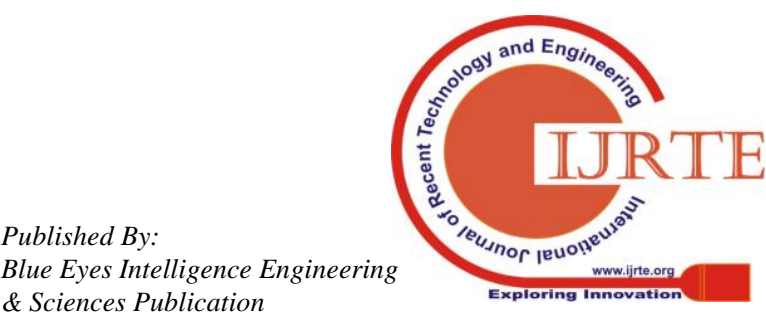


E - HR choices should be flexible in order to ensure that staff feel comfortable while using such a scheme.

- Better organisational structure to guarantee effective execution of E - HRM with E - HRM should be taken into account.

Employer branding will increase in the company globe through the use of social sites in the recruitment process.

Companies should have documents and predict popularity and wise use of social networking sites.

The use of social recruitment sites needs site maintenance to guarantee that requests are answered in a comparatively timely manner and sites are updated.

Promote the beneficial use of social media by encouraging staff to find methods to make better use of the instruments of the social site to do employment.

\section{CONCLUSION}

Social media provides multiple HR features with a fresh platform. Candidates ' hiring and screening are the fields in which social media makes their presence felt. Recruitment organisations, consistent with the brand and approach of the organisations, can target candidates, source passive and active applicantsThus working with the correct applicants will offer an advantage over their rivals to the organisation. These sites are great for collaboration and brand image creation in addition to this. Individual or business can demonstrate their worth by updating and projecting themselves frequently by strengthening organizational identification and supporting the brand. These sites also contribute to data and awareness creation and generation. Companies can also share the strategies using this platform. However, there are certain difficulties connected with using this medium with the various possibilities. Organization needs to understand that staff are competent in coping with data abundance and inner organisational policies are up-to-date Data plan and equipment reimbursement. It is necessary to strategically frame policies and raise awareness about the use of social media to cope with this organisation, train executives on the social media strategy of the company, document all policies, processes and practices. As is currently the case, avoiding these networking sites will not be a feasible option for businesses.

\section{REFERENCES}

1) BharthVajan R., Ramachandran S.,Psychographic dimensions of training,2016,International Journal of Pharmacy and Technology,V-8,I-4,P-23727-23729

2) Balakrishnan P., Bharthvajan R.,A study on human resource planning in hospitals in Chennai City,2014,International Journal of Applied Engineering Research,V-9,I-22,P-7503-7507

3) Priyadarsini P., Bharthvajan R.,Role of emotional intelligence training programme in reducing the stress of the nurses,2014,International Journal of Applied Engineering Research,V-9,I-22,P-7411-7421

4) Kerinab Beenu G., Bharthvajan R.,Empirical analysis on the cosmetic buying behavior of young women in South India,2014,International Journal of Applied Engineering Research,V-9,I-22,P-7361-7366

5) Balakrishnan P., Bharthvajan R.,Whistling in the wind,2014,International Journal of Applied Engineering Research,V-9,I-22,P-7586-7593

6) Krishnan B., Peter M.,Health hazards of Indian Bpo employee-an alarming issue,2014,International Journal of Applied Engineering Research,V-9,I-22,P-7336-7341

7) Kerinab Beenu G.H., Peter M.,Role of insurance in economic development,2014,International Journal of Applied Engineering Research,V-9,I-22,P-7532-7539

8) Balakrishnan P., Peter M., Priyadarsini P.,Efficiency of safety measures for wellbeing of employees in manufacturing industry,2014,International Journal of Applied Engineering Research,V-9,I-22,P-7376-7382

9) Anbarasi M., Praveen Kumar S.,Online sales promotions of herbal products and its effectiveness towards tanisha.com,2019,Indian Journal of Public Health Research and Development,V-10,I-1,P-195-200

10) Anbarasi M., Praveen Kumar S.,Various online marketing and promotions strategies to improve the validation towards the organic products in the pharmaceutical sectors,2019,Indian Journal of Public 11) Loganathan R., Praveen Kumar S.,Grievance handling a key factor for solving issues of employees in an organization,2014,International Journal of Applied Engineering Research,V-9,I-22,P-7483-7491

12) Loganathan R., Praveen Kumar S.,Study on preference of private label brands in super and Hypermarkets,2014,International Journal of Applied Engineering Research,V-9,I-22,P-7327-7335

13) Smitha M., Praveen Kumar S.,Understanding stress and its managementamong the nurses in Chennai city,2014,International Journal of Applied Engineering Research,V-9,I-22,P-7560-7565

14) Kerinab Beenu G.H., Praveen Kumar S.,A study on the investment behavior of Chennai investors in mutual fund schemes,2014,International Journal of Applied Engineering Research,V-9,I-22,P-7520-7525

15) Loganathan R., Praveen Kumar S.,Retention strategies key for organizational productivity,2014,International Journal of Applied Engineering Research,V-9,I-22,P-7443-7447

16) Pavithra J., Ganesan M., Brindha G.,State wise analysis of microfinance sector in India,2016,International Journal of Pharmacy and Technology,V-8,I-4,P-23417-23432

17) Pavithra J., Ganesan M.,A comparative study on microfinance in India and abroad,2016,International Journal of Applied Business and Economic Research,V-14,I-8,P-5471-5476

18) Pavithra J., Ganesan M.,A study on awareness and impact of micro-financial schemes,2016,International Journal of Applied Business and Economic Research,V-14,I-8,P-5449-5460

19) Senthilmurugan P., Pavithra J.,Consumer preference towards organised retailing with reference to Big Bazaar,2014,International Journal of Applied Engineering Research,V-9,I-22,P-7469-7475

20) Senthilmurugan P., Pavithra J.,Implication of social media marketing in growing healthcare industry,2014,International Journal of Applied Engineering Research,V-9,I-22,P-7448-7456

21) Loganathan R., Pavithra J.,Consumer perception towards private label brand over other brands in super markets and hypermarkets,2014,International Journal of Applied Engineering Research,V-9,I-22,P-7355-7360

22) Kerinab Beenu G., Pavithra J.,Tradeâ€"off between liquidity and profitability in logistics industry,2014,International Journal of Applied Engineering Research,V-9,I-22,P-7398-7401

23) Kerinab Beenu G., Pavithra J.,A study on the prospective consumerâ $€^{\mathrm{TM}_{\mathrm{S}}}$ perception towards utility cars in Chennai city,2014,International Journal of Applied Engineering Research,V-9,I-22,P-7526-7531

24) Pavithra J., Dilli Babu P., Ambuli T.V.,A study on budgetary control at Maruti Service Masters, Chennai,2014,International Journal of Applied Business and Economic Research,V-12,I-2,P-151-161

25) Pavithra J., Dilli Babu P., Ambuli T.V.,A study on customer satisfaction of retro Garments Pvt Ltd, Chennai,2014,International Journal of Applied Business and Economic Research,V-12,I-2,P-381-391

26) Kerinab Beenu G.H., Pavithra J., Senthilmurugan P.,A study on the influence of promotional activities for TATA ARIA among consumers in Chennai,2014,International Journal of Applied Engineering Research,V-9,I-22,P-7572-7578

27) Vijayaragavan S.P.,An investigative expert that's general FBG sensors, International Journal of Mechanical Engineering and Technology,V-8,I-8,PP-1500-1505,Y-2017

28) Vijayaragavan S.P.,Equalization routing protocol for Wi-Fi sensor strategy,International Journal of Mechanical Engineering and Technology,V-8,I-8,PP-1662-1666,Y-2017

29) Karthik B., Kiran Kumar T.V.U., Vijayaragavan P., Bharath Kumaran E.,Design of a digital PLL using 0.35 $\hat{\mathrm{I}}^{1} / 4 \mathrm{~m}$ CMOS technology,Middle East Journal of Scientific Research,V-18,I-12,PP-1803-1806,Y-2013

30) Kanniga E., Selvaramarathnam K., Sundararajan M.,Kandigital bike operating system,Middle - East Journal of Scientific Research,V 
31) Jasmin M., Vigneshwaran T., Beulah Hemalatha S.,Design of power aware on chip embedded memory based FSM encoding in FPGA,International Journal of Applied Engineering Research,V-10,I-2,PP-4487-4496,Y-2015

32) Jasmin M.,Optimization techniques for low power VLSI circuits,Middle - East Journal of Scientific Research,V-20,I-9,PP-1082-1087,Y-2014

33) Jasmin M., Vigneswaran T.,Fuzzy controller for error control of on Chip communication,2017 International Conference on Algorithms, Methodology, Models and Applications in Emerging Technologies, ICAMMAET 2017,V-2017-January,I-,PP-1-5,Y-2017

\section{AUTHORS PROFILE}

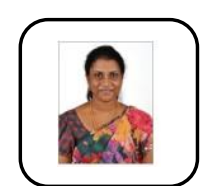

Magdalene Peter,Assistant Professor, Department of Management Studies ,Bharath Institute of Higher Education and Research.

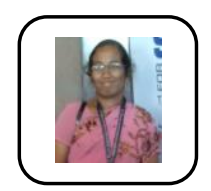

JPavithra ,Assistant Professor, Department of Management Studies, Bharath Institute of Higher Education and Research.

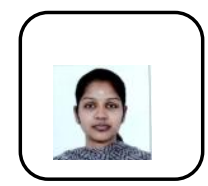

Renju ,Student, Department of Management Studies,Bharath Institute of Higher Education and Research. 